\title{
Correlation of Oxidative Stress and Hepatoprivial Syndrome in Dogs with Comorbidity of Babesiosis and Dirofilariasis
}

\section{Tatyana Ushakova ${ }^{1}$, Tatyana Derezina ${ }^{2}$, Ivan Kapelist ${ }^{2}$, Galina Zelenkova ${ }^{2}$, and Vera Kolodenskaya}

${ }^{1}$ Federal State Budget Educational Institution of Higher Education "Don State Agrarian University", Persianovsky, Russian Federation

${ }^{2}$ Federal State Budget Educational Institution of Higher Education "Don State Technical University", Rostov-on-Don, Russian Federation

ORCID:

Tatyana Ushakova: http://orcid.org/0000-0002-8634-268X

\section{Abstract}

The comorbidity of babesiosis and dirofilariasis in dogs is an important clinical problem, despite the significant achievements of recent years in understanding the pathogenesis

Corresponding Author:

Tatyana Ushakova

tanja_0802@mail.ru

Published: 5 April 2021

Publishing services provided by

Knowledge E

(c) Tatyana Ushakova et al. This article is distributed under the terms of the Creative Commons Attribution License, which permits unrestricted use and redistribution provided that the original author and source are credited.

Selection and Peer-review under the responsibility of the DonAgro Conference Committee. of this mixed invasion. It has been established that the leading pathogenetic component in the development of the cytolytic syndrome with this comorbidity in dogs is oxidative stress resulting from the mismatch of the prooxidant and antioxidant resources of the cell under the influence of Babesia canis parasitism. On the basis of morphological, biochemical and ultrasonographic studies, a direct correlation was found between oxidative stress and hepatoprivial syndrome in dogs with comorbidity of babesiosis and dirofilariasis. Hepatoprivial syndrome was accompanied by the development of hypochromic anaemia, leukocytosis, hyperproteinemia, hypoglycemia, a disorder of pigment metabolism and an increase in the catalytic activity of serum enzymes, which indicated a violation of the metabolic activity of the liver and damage to its parenchyma. The activation of lipid peroxidation processes in the hepatocytes contributed to an increase in the catalytic activity of the blood serum enzymes in sick animals, and to a decrease in the antioxidant defence of sick dogs, due to a relative decrease in the level of vitamin A in the blood. Thus, the comorbidity of babesiosis and dirofilariasis in dogs enhances the oxidative syndrome that underlies the pathogenetic mechanisms of this mixed invasion, thereby increasing the degree of involvement in the pathological process of the liver, which is manifested by hepatoprivial syndrome.

Keywords: oxidative stress, hepatoprivial syndrome, dirofilariasis, babesiosis, mixtinvasion, dogs.

\section{Introduction}

Long-term studies have proved that the classical clinical picture of many diseases in modern conditions undergoes changes and gradually loses its typicality. The reason 
of associations. In all biological systems, the process of self-organization necessarily proceeds with the participation of a large number of objects of various types. Therefore, the question of the comorbidity of diseases is the result of the existence of a biological system. This circumstance gives reason to put forward the assumption that monoinvasions not only do not occur in the animal kingdom but any infectious disease, in principle, cannot occur without the mutual influence of other pathogens on it [1].

This problem is especially acute among vector-borne diseases. Russia is one of the vastest countries, on the territory of which blood-sucking insects are almost universally distributed. This state of affairs creates the prerequisites for the existence of associative natural foci [2-4].

Prerequisites for the comorbidity of babesiosis and dirofilariasis are polymorphism of manifestations of dog babesiosis and the persistence of parasites in animals. This issue is an important clinical problem, despite the significant achievements of recent years in understanding the pathogenesis of this mixtinvasion. Also, the problem of the mechanism of the development of the association remains open. There are also many unresolved issues in the diagnosis of the disease, therapy and prevention of this mixtinvasion [5].

It can be argued that oxidative stress is the leading pathogenetic component in the development of the cytolytic syndrome in babesiosis in dogs. This stress arises as a result of the prooxidant mismatch and antioxidant resources of the cell under the influence of parasitism of Babesiacanis. Besides, a violation of the homeostatic mechanisms of oxidative metabolism of the body is considered recently as an independent syndrome [6].

Thus, it can be argued that the comorbidity of babesiosis and dirofilariasis makes it difficult both to choose methods of therapeutic correction [7 - 9] and to predict the course of this association [10-12]. A set of treatment and prophylactic measures cannot be fully implemented for many reasons: chronicity of this pathology, complications associated with intoxication, impaired metabolic function of the liver and involvement of components of the cardiopulmonary and hepatorenal systems in the pathological process [13 - 15].

Our research aimed to study the correlation level of oxidative stress and hepatoprivial syndrome in dogs with the associative course of babesiosis and dirofilariasis. Taking into account the peculiarities of the etiopathogenetic aspects of the disease, to achieve the intended goal, we set the following tasks: to study the clinical status, morphological, biochemical blood parameters, ultrasonographic studies of the hepatobiliary system in dogs with mixtinvasive dirofilariasis - babesiosis, with signs of hepatopriva syndrome. 


\section{Methods and Equipment}

The work was performed during 2019-2020 at the Department of Therapy and Propaedeutics of the Don State Agrarian University (Persianovsky village) and the Vitavet Veterinary Clinic (Novocherkassk city).

In order to carry out research, experimental and control groups of animals were formed. In each group, there were ten large-breed dogs aged 3.5 to 4 years, patients with mixtinvasion, dirofilariasis-babesiosis with signs of hepatoprivial syndrome. The groups were formed based on pairs of analogues as animals entered the veterinary clinic. The diagnosis was made based on anamnesis, the results of a clinical study, laboratory blood tests and microscopy of peripheral blood smears. A clinical study of sick animals was carried out according to standard methods.

In order to confirm the diagnosis of dirofilariasis in dogs, a blood smear was examined, and an immunochromatographic method was used. For the final diagnosis of babesiosis, microscopy of smears of the peripheral blood of dogs was performed. Ultrasonographic studies of the hepatobiliary system in sick animals were performed on a MindrayUMT150 apparatus. At the same time, they were evaluating the size, structure of the liver, gall bladder, as well as the presence of free fluid in the abdominal cavity.

In the blood, the content of erythrocytes, leukocytes, the concentration of hemoglobin on a veterinary hematological analyzer PCE-90 VET, and the erythrocyte sedimentation rate were determined. The level of total serum protein, albumin, glucose, total bilirubin, direct bilirubin, creatinine, urea, alanine aminotransferase, aspartate aminotransferase, cholinesterase, amylase, alkaline phosphatase was determined using a BIOBASE-8021A automatic biochemical analyzer. To determine the level of vitamin $A$, the quantitative method of O. A. Bessie in the modification of A. A. Anisova was used.

\section{Results}

As a result of clinical trials of sick animals, signs of apathy, anorexia and polydipsia were revealed. An increase in body temperature was observed in dogs of the experimental group to $40.9 \pm 0.5^{\circ} \mathrm{C}$. In the control group to $41.1 \pm 0.4^{\circ} \mathrm{C}$. An increase in heart rate was recorded to $182 \pm 2.0$ beats per minute in the experimental group and $185 \pm 3.0$ beats per minute. In control, the respiratory rate reached $35 \pm 4.0$ respiratory movements per minute and $36 \pm 2.0$ respiratory movements per minute, respectively. In animals, icteric staining of the mucous membranes of the oral cavity, conjunctiva of the eyes was 
observed, urine was red. Also, in sick dogs, dehydration, salivation, vomiting, shortness of breath during physical exertion were detected.

Microscopic examination of peripheral blood smears of sick animals stained according to Romanowski Giemsa visualized paired pear-shaped forms of Babesia canis canis in red blood cells, and parasitemia reached 1\% (Figure 1b). Microfilariae Dirofilaria immitis in blood was detected in sick dogs using a saturated smear method (Figure 1a).

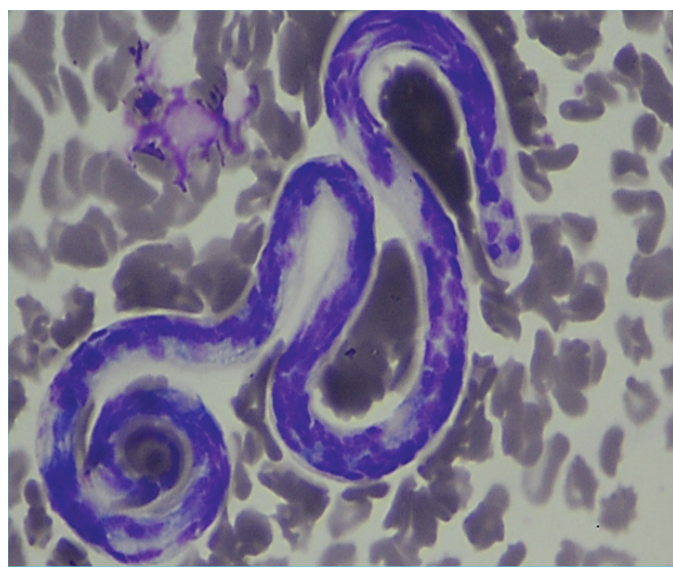

a

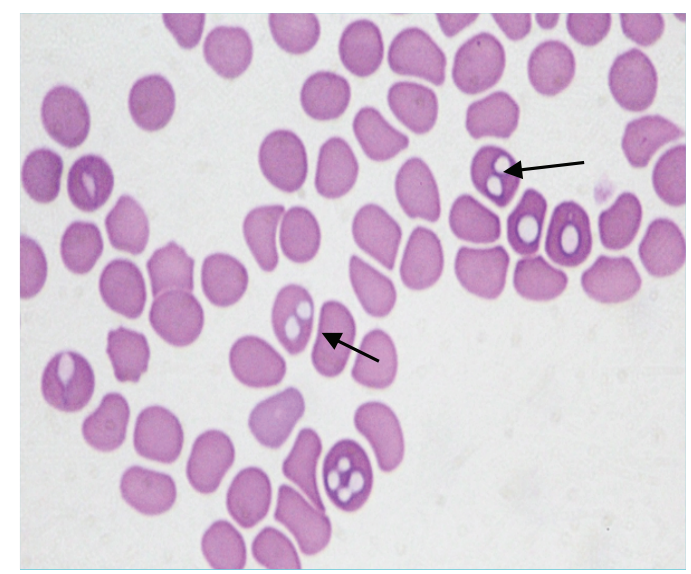

$\mathrm{b}$

Figure 1: A micrograph of the blood of a dog with the comorbidity of babesiosis and dirofilariasis, microfilaria Dirofilariaimmitis (a); paired pear-shaped forms of Babesia canis canis (b).

As a result of sonographic studies of the hepatobiliary system of dogs with mixtinvasion, dirofilariasis-babesiosis, diffuse changes in the parenchyma of the type of acute hepatitis were revealed. An increase in the size of the liver was noted, its edges were rounded, and the contour was even. A decrease in the echogenicity of the liver parenchyma, an increase in the vascular pattern, and an expansion of the venous component were recorded.

Data on the morphological parameters of blood in dogs of both groups indicated the development of hypochromic anaemia, with hemoglobin levels reaching $85.90 \pm 5.17$ $\mathrm{g} / \mathrm{dl}$ in the experimental group and $87.80 \pm 4.89 \mathrm{~g} / \mathrm{dl}$ in control and erythrocytes 4.80 $\pm 0.21 \times 10^{12} / /$ and $4.50 \pm 0.18 \times 10^{12} / /$, respectively. Signs of leukocytosis $(16.10 \pm 0.58$ $\times 10^{9} / /$ and $\left.15.80 \pm 0.42 \times 10^{9} / I\right)$ were recorded (Table 1$)$.

Thus, the erythrocyte count in dogs of the experimental group was lower than the arithmetic average of the reference values by $29.41 \%$, and the control - by $33.82 \%$, the haemoglobin value was lower by $40.76 \%$ and $39.45 \%$, respectively.

The erythrocyte sedimentation rate increased to $11.90 \pm 1.01 \mathrm{~mm} / \mathrm{h}$ in the experimental group, and in the control - to $12.15 \pm 1.04 \mathrm{~mm} / \mathrm{h}$. 
TABLE 1: Morphological blood counts in dogs with comorbidity and dirofilariasis and babesiosis $(\mathrm{X} \pm \mathrm{Sx}$ ).

Indicators

Erythrocytes, $\times 10^{12} / 1$

Leukocytes, $\times 10^{9} / /$

Hemoglobin, g/dl

The erythrocyte sedimentation rate, $\mathrm{mm} / \mathrm{h}$

Comment: ${ }^{*} \mathrm{P}<0,05$; $^{* *}-\mathrm{P}<0,01 ;{ }^{* * *}-\mathrm{P}<0,001$

\begin{tabular}{|c|c|c|}
\hline \multicolumn{3}{|c|}{ Group of animals $(n=10)$} \\
\hline $\begin{array}{c}\text { Experienced } \\
\text { Group }\end{array}$ & Control group & Reference values \\
\hline $4.80 \pm 0.21^{*}$ & $4.50 \pm 0.18^{*}$ & $\frac{5.2-8.4}{(6.8)}$ \\
\hline $16.10 \pm 0.58$ & $15.80 \pm 0.42$ & $\frac{8.0-17.0}{(12.5)}$ \\
\hline $85.90 \pm 5.17^{*}$ & $87.80 \pm 4.89^{*}$ & $\frac{110-180}{(145)}$ \\
\hline $11.90 \pm 1.01^{*}$ & $12.15 \pm 1.04^{*}$ & $\frac{2-8}{(5)}$ \\
\hline
\end{tabular}

As a result of biochemical studies of the blood of sick animals, significant biochemical changes were revealed, indicating the development of hepatoprivial syndrome and impaired hepatorenal system function, which is shown in Table 2.

TABLE 2: Blood biochemical parameters in dogs with comorbidity of dirofilariasis and babesiosis $(X \pm S x)$.

Indicators
Total protein, g/l
Albumins, g/l
Glucose, $\mathrm{mmol} / \mathrm{I}$
Urea, mmol/I
Creatinine, mmol/I
Alkaline phosphatase, U/I
Alanine aminotransferase, U/I
Aspartate aminotransferase, U/I
Cholinesterase, mmol/I
Amylase, U/I
Total bilirubin, Imol / I
Straight bilirubin, $\mu$ mol / I
Vitamin A, $\mu$ mol / I

\begin{tabular}{|c|c|c|}
\hline \multicolumn{3}{|c|}{ Group of animals $(n=10)$} \\
\hline $\begin{array}{c}\text { Experienced } \\
\text { Group }\end{array}$ & Control group & Reference values \\
\hline $75.20 \pm 1.14^{*}$ & $76.15 \pm 1.35^{*}$ & $\frac{54-73}{(63.5)}$ \\
\hline $23.80 \pm 0.84$ & $24.20 \pm 1.13$ & $\frac{22-39}{(30.5)}$ \\
\hline $3.60 \pm 0.22^{*}$ & $3.80 \pm 0.25^{*}$ & $\frac{4.3-6.7}{(5.5)}$ \\
\hline $15.70 \pm 0.42^{* *}$ & $16.00 \pm 0.38^{* *}$ & $\frac{3,5-10,5}{(7)}$ \\
\hline $125.70 \pm 6.03^{* *}$ & $123.10 \pm 7.09^{* *}$ & $\frac{61.9-106.1}{(84)}$ \\
\hline $98.30 \pm 5.48^{*}$ & $103.40 \pm 6.02^{* *}$ & $\frac{19-90}{(54.5)}$ \\
\hline $103.10 \pm 1.08^{* *}$ & $99.90 \pm 1.19^{* *}$ & $\frac{15-62}{(38.5)}$ \\
\hline $72.60 \pm 2.11^{* *}$ & $73.80 \pm 2.26^{* *}$ & $\frac{16-43}{(29.5)}$ \\
\hline $208.30 \pm 2.30^{*}$ & $210.10 \pm 1.80^{*}$ & $\frac{340-360}{(350)}$ \\
\hline $1815.6 \pm 62.16$ & $1821.3 \pm 71.75$ & $\frac{685-2155}{(1420)}$ \\
\hline $13.8 \pm 1.15^{* *}$ & $12.5 \pm 0.90^{* *}$ & $\frac{1.7-10.6}{(6.15)}$ \\
\hline $5.9 \pm 1,14^{*}$ & $6.3 \pm 1,25^{*}$ & $\frac{0-5.5}{(2.75)}$ \\
\hline $0.01 \pm 0.001$ & $0.01 \pm 0.003$ & $\frac{0.01-0.03}{(0.02)}$ \\
\hline
\end{tabular}

Comment: * $\mathrm{P}<0,05$; $^{* *}-\mathrm{P}<0,01 ;{ }^{* * *}-\mathrm{P}<0,001$

In animals, hyperproteinemia $(75.20 \pm 1.14 \mathrm{~g} / \mathrm{I}$ and $76.15 \pm 1.35 \mathrm{~g} / \mathrm{I})$ and hypoglycemia $(3.60 \pm 0.22 \mathrm{mmol} / \mathrm{I}$ and $3.80 \pm 0.25 \mathrm{mmol} / \mathrm{l})$ were observed in animals. Moreover, the deviation of glycogenesis processes in sick animals in the experimental group was $34.54 \%$, and in the control group, it was 30.91\% compared with the arithmetic average of the reference values. 
The urea and creatinine values exceeded the reference values, and amounted to $15.70 \pm 0.42 \mathrm{mmol} / \mathrm{I}$ and $125.70 \pm 6.03 \mathrm{mmol} / \mathrm{I}$ in the experimental group, $16.00 \pm$ $0.38 \mathrm{mmol} / \mathrm{I}$ and $123.10 \pm 7.09 \mathrm{mmol} / \mathrm{I}$ in control, respectively. A significant increase in the level of total and direct bilirubin in dogs was observed during the associative course of dirofilariasis and babesiosis up to $13.8 \pm 1.15 \mu \mathrm{mol} / \mathrm{l}$ and $5.9 \pm 1.14 \mu \mathrm{mol} / \mathrm{I}$ in the experimental group, and up to $12.5 \pm 0.90 \mu \mathrm{mol} / \mathrm{l}$ and $6.3 \pm 1.25 \mu \mathrm{mol} / \mathrm{I}$ in control, respectively.

The catalytic activity of serum enzymes in animals of both groups was characterized by an increase in the level of alanine aminotransferase (103.10 $\pm 1.08 \mathrm{U} / \mathrm{I}$ and $99.90 \pm$ $1.19 \mathrm{U} / \mathrm{I})$, aspartate aminotransferase $(72.60 \pm 2.11 \mathrm{U} / \mathrm{I}$ and $73.80 \pm 2.26 \mathrm{U} / \mathrm{I})$, which are organ-specific enzymes hepatocytes, and are released when cells are damaged, as well as alkaline phosphatase (98.30 $\pm 5.48 \mathrm{U} / \mathrm{I}$ and $103.40 \pm 6.02 \mathrm{U} / \mathrm{I})$ and amylase $(1815.6 \pm 62.16 \mathrm{U} / \mathrm{I}$ and $1821.3 \pm 71.75 \mathrm{U} / \mathrm{l})$. The cholinesterase index in dogs of both groups was reduced $(208.30 \pm 2.30 \mathrm{mmol} / \mathrm{I}$ and $210.10 \pm 1.80 \mathrm{mmol} / \mathrm{l})$. The level of vitamin $A$ in the blood of sick animals $(0.01 \pm 0.001 \mu \mathrm{mol} / \mathrm{I}$ and $0.01 \pm 0.003 \mu \mathrm{mol} / \mathrm{I})$ corresponded to the lower reference values.

\section{Discussion}

Against the background of leukocytosis in dogs with the comorbidity of babesiosis and dirofilariasis, the development of hypochromic anaemia was due to impaired hematopoiesis and red blood cell lysis due to parasitization of Babesiacanis. Also, the massive breakdown of red blood cells and the release of haemoglobin, which breaks down in the liver to bilirubin, caused an increase in the level of direct and total blood bilirubin.

An increase in the erythrocyte sedimentation rate index indicated the development of intoxication in dogs. Besides, this indicator acts as a marker of dysproteinemia due to a violation of the protein-synthesizing function of the liver. The development of hyperproteinemia was due to a violation of the metabolic activity of the liver and damage to its parenchyma. These facts were confirmed by the results of ultrasonographic studies of the hepatobiliary system.

The catalytic activity of serum enzymes in animals of both groups was characterized by the release into the blood of both cytosol enzymes and enzymes of the biliary pole of hepatocyte membranes. These processes were caused by the activation of lipid peroxidation processes in hepatocytes against the background of inhibition of the adaptive reactions of the antioxidant defence system of animals with the comorbidity 
of babesiosis and dirofilariasis. These changes caused the acceleration of apoptotic processes in hepatocytes and led to systemic membranopathy with the development of regenerative-plastic insufficiency syndrome. As a result of this process, the barrier and detoxic functions of the liver are impaired, hypoxic phenomena arose, and inflammatory processes progressed. Also, a relatively low level of vitamin $A$ in the blood indicates a decrease in the antioxidant defence of the body of sick dogs.

A decrease in cholinesterase levels confirmed the involvement of the liver parenchyma in the pathological process and the massive death of hepatocytes. An increase in serum alanine aminotransferase activity was associated with the involvement of the liver parenchyma in the inflammatory process since it is precise as a result of damage to hepatocytes that this enzyme enters the blood plasma of sick animals. This indicator also acts as an indicator of the degree of damage to the hepatic parenchyma and the duration of the pathological process affecting the structure of the liver. Also, a simultaneous increase in the activity of alanine aminotransferase, aspartate aminotransferase, alkaline phosphatase and amylase, as well as an increase in the level of total and direct bilirubin, indicates toxic liver damage with the development of cholestasis, cholecystitis and acute pancreatitis.

An increase in creatinine and urea levels indicated impaired renal filtration and the development of acute renal failure in dogs with comorbidity of dirofilariasis and babesiosis, due to the involvement of the hepatorenal system in the pathological process.

\section{Conclusion}

Thus, with the comorbidity of babesiosis and dirofilariasis, the leading trigger of oxidative stress is the parasite Babesiacanis. Therefore, lipid peroxidation processes affect the structure of the hepatorenal system primarily and not cardiopulmonary. Also, oxidative stress correlates with the degree of involvement of hepatocytes in the pathological process, which leads to the development of hepatoprivial syndrome with the involvement of structures of the hepatorenal system.

\section{Conflict of Interest}

The authors have no conflict of interest to declare. 


\section{References}

[1] Lutsuk, S. N., Temichev, K. V. and Ponomareva, M. Y. (2015). The course of dogs babesiosis in mono- and myxinvasion with leptospirosis. Bulletin of the AgroIndustrial Complex of Stavropol, vol. 20, pp. 99-105.

[2] Bespalova, N. S., Stepkin, Y. I. and Zolotykh, T. A. (2016). New aspects of the epizootology and epidemiology of dirofilariasis in the Central Black Earth Region of Russia. Veterinary Pathology, vol. 55, pp. 23-30.

[3] Kartashov, S. N., Klyuchnikov, A. G. and Butenkov, A. I. (2015). Vector infections of dogs, clinical and morphological aspects of babesiosis in dogs in the Rostov Region. Veterinary Pathology, vol. 3, pp. 10-16.

[4] Mezentsev, S. V. (2013). Epizootology of dog dirofilariasis in Altai Territory. Bulletin of Altai State Agrarian University, vol. 103, pp. 110-113.

[5] Sarma, K., et al. (2015). Therapeutic management of concomitant infection of dirofilariasis, ehrlichiasis and anaplasmosis in a dog. Indian Veterinary Journal, vol. 92, pp. 30-33.

[6] Martusevich, A. K. and Karuzin, K. A. (2015). Oxidative stress and its role in the formation of maladaptation and pathology. Bioradicals and Antioxidants, vol. 2, pp. $42-53$.

[7] Zolotykh, T. A. (2015). Modern laboratory methods for the diagnosis of carnivorous dirofilariasis. Proceedings of the Kostroma State Agricultural Academy, vol. 1, pp. 62-66.

[8] Gracious, M. S. (2012). To the question of piroplasmosis of dogs. Veterinary Medicine of the Kuban, vol. 5, pp. 13-14.

[9] Khristianovsky, P. I. (2017). Dog babesiosis (review of scientific literature). Innovation in Agriculture, vol. 22, pp. 279-285.

[10] Chanysheva, M. R. (2013). Dog pyroplasmosis: approaches to diagnosis and treatment. J. Actual problems of Veterinary Medicine, vol. 1, pp. 315-315.

[11] Johan, S. and Masahiro, Y. (2015). Canine babesiosis. Journal of the Japan Veterinary Medical Association, vol. 68, pp. 245-252.

[12] Davitkov, D. and Vucicevic, M. J. Stevanovic et al., (2015). Clinical babesiosis and molecular identification of Babesia canis and Babesia gibsoni infections in dogs from Serbia. Acta Veterinaria Hungarica, vol. 63, pp. 199-208.

[13] Beugnet, F. and Moreau, Y. (2015). Babesiosis. Revue Scientifique et Technique de I'OIE, vol. 34, pp. 627-639. 
[14] Staniec, M. (2010). From piroplasmosis to babesiosis-problems with classification of Babesia protozoa isolated from dogs. Wiadomosci Parazytologiczne, vol. 56, pp. $111-115$.

[15] Solano-Gallego, L. and Baneth, G. (2011). Babesiosis in dogs and cats-Expanding parasitological and clinical spectra. Veterinary Parasitology, vol. 181, pp. 48-60. 